\title{
THE ROLE OF PARTY: THE LEGISLATIVE CONSEQUENCES OF PARTISAN ELECTORAL COMPETITION
}

\author{
Royce Carroll \\ Department of Political Science \\ Rice University \\ Houston, TX \\ rcarrollorice.edu \\ Jason Eichorst \\ Department of Political Science \\ Rice University \\ Houston, TX \\ jaeichorst@rice.edu
}

\begin{abstract}
We examine the proposition that legislative organization can be explained by the nature of party competition in elections. We argue that legislators in environments where two parties are competitive for majority status should be most likely to have delegated power to their leadership to constrain individualistic behavior within their party, which should in turn increase the spatial predictability of individual voting patterns. Using roll call votes and district-level electoral data from the U.S. state legislatures, we show empirically that increased statewide interparty competition strongly corresponds to much more predictable voting behavior overall, while legislators from competitive districts have the least predictable behavior.
\end{abstract}




\section{INTRODUCTION}

Recent work on parties in legislatures, especially that drawing on Cox \& McCubbins (1993), has suggested that parties' incentives to organize legislatures are in large part a function of a collective electoral strategy. According to this view, parties should organize for the collective goal of protecting and developing a party reputation. Party reputations indeed can provide a valuable basis for voters to make choices (Rahn 1993, Schaffner \& Streb 2002, Woon \& Pope 2008), but for a party to contest elections as a group it must develop a coherent record of behavior (Kiewiet \& McCubbins 1991, Smith 2000). This means organizing a legislative party such that individual actions to win support from local constituencies and interest groups do not undermine the party record. At the same time, many legislators, especially those from competitive districts, rely substantially on their personal reputations to win elections (Mayhew 1974) and therefore must respond to unique district interests in order to strengthen their own chances of reelection (Canes-Wrone, Brady \& Cogan 2002). To limit the potential for these incentives to undermine party goals, Cox \& McCubbins (1993) emphasize the importance of delegating power to allow leaders to manage their organizations.

Extending this literature, we suggest that these motivations will depend upon the nature of party competition. Specifically, the incentives for parties to develop clearer collective reputations should be strongest in chambers where the majority and minority parties are in close competition, even when this may be individually costly for legislators from competitive districts. In such situations, where majority control can easily change hands as a result of a given election, party members have far more to gain from delegating to their party leadership the power to create and protect a party record. As a result, while individual legislators from competitive electoral districts should have the most idiosyncratic behavior within their parties, parties as a whole should be more likely to reduce these tendencies when facing more competitive electoral environments at the party level.

The cross-sectional variation in party systems and legislative behavior in the U.S. state assemblies provides a useful venue with which to evaluate the foundations of legislative organization theory. We build on the previous literature on legislative parties to explain how 
the conflicting incentives between party and individual goals are reconciled. We argue that a party's organizational response to this tension is conditional on the competitive environment faced by parties collectively. To examine this question empirically, we use individual-level cross-sectional data on roll call voting and elections in the U.S. state assemblies from 1999 to 2000. We focus on deviations from unidimensional behavior, as captured by the individual "error" rates generated by roll call predictions from the W-NOMINATE spatial voting model. We use these error rates to capture the degree to which each member's voting responds to non-ideological or "multi-dimensional" pressures which result in voting that is poorly predicted by a spatial model. With this data, we examine how party competition along with individual district circumstances explains the coherence of legislative behavior.

We find members in competitive districts indeed have less predictable legislative voting within their parties. However, among parties as groups, we find that there is a consistent relationship between the competitiveness of the state party system and the degree to which political parties collectively display coherent voting behavior. We also find that majority party members tend to have more coherent voting behavior on average. We interpret these empirical results to suggest that while parties generally tend to be more coherent in competitive systems, majority parties may be better able to exploit chamber control to structure the voting patterns of their members.

\section{Party Versus Individual Electoral InCEntives}

Much literature on Congress suggests that a key motivation for parties to actively organize in legislatures stems from the electoral strategy to cultivate a party reputation (Cox \& McCubbins 1993, Hager \& Talbert 2000, Sinclair 1995, Snyder \& Ting 2002, Woon \& Pope 2008). This literature suggests that one of the most important ways parties cultivate a reputation is by creating a coherent party voting record. These records of behavior establish "greater consistency in positions across issues" (Kiewiet \& McCubbins 1991, 40) and increase the informational value of the party label. A strong party reputation signals the policies a political party would pursue and enables the electorate to hold parties accountable for 
policy, enabling a "responsible" party system (American Political Science Association 1950). However, not all members benefit directly from cultivating strong party reputations and many face competing pressures.

Individual Strategy and Party Response. First, individual members may have an incentive to avoid allowing their behavior to be constrained. Legislators elected from individual districts generally have incentives to improve their own chance of reelection (Mayhew 1974, Berry, Berkman \& Schneiderman 2000). Often this means behaving in alignment with one's district (Canes-Wrone, Brady \& Cogan 2002, Carson et al. 2010) and building an electoral coalition in the district (Ansolabehere, Snyder \& Stewart 2001, Snyder \& Ting 2003). ${ }^{1}$ This might mean voting in line with regional economic concerns or other local interests, which will shift depending on how these constituents are affected by an issue and with the salience of the issue (Bishin 2009).

This behavior is distinct from "moderation" or a lack of party-line voting, as parties expect their members to respond to their district's policy preferences. Rather, it reflects an issue-by-issue consideration of district interests. Building a favorable personal reputation in the district separate from ideology means responding to pivotal interest groups who "press upon the candidate some special claim" (Schlesinger 1991, 136). In the aggregate, and in the absence of party constraints, this means independent legislators will join shifting coalitions in the chamber as is necessary to cater to various constituencies in the district. This may entail voting more with ad hoc coalitions or a tendency to trade votes on policy for narrow distributive benefits (Evans 1994, Evans 2004). For this reason, we would expect to observe highly complex voting environments in the absence of parties (Jenkins 1999, Wright \& Schaffner 2002).

Given these demands, legislators have good reason not to support empowering parties with the authority to restrict their choices. Rather, legislators should prefer minimal constraints

\footnotetext{
${ }^{1}$ Individual voting records may play a smaller direct role in state elections than Congress, due to a lower information environment (Hogan 2008), which may make party organization generally less costly to develop. Nevertheless, voting behavior still remains as one of the few tools with which these legislators can directly establish a reputation among their constituents.
} 
on their voting behavior. Even if party goals are valuable, these goals are public goods lacking incentives for spontaneous cooperation. However, parties can limit the incentives and opportunities of members to participate in ad hoc voting coalitions that would harm the party record. At least for those facing the fewest pressures to join shifting coalitions in the chamber-those in electorally "safer" districts-incentives such as committee assignments or campaign resources can balance potential electoral costs from party-constrained behavior. Even in the context of well-organized parties, legislators facing incentives to join shifting coalitions should display more complex voting behavior. In other words, a party organization need not achieve strict party unity in order to avoid widespread opportunistic behavior, but should impose constraints primarily on members with the least electoral "need" for an independent reputation.

Collective Strategy and Party Reputation. Even if parties can empower their leadership to constrain the choices of members, they do not necessarily have an incentive to do so. While Cox \& McCubbins (1993, 2005) argue that parties should actively prevent behavior that undermines the party label, this argument follows from the assumption that the party label is consistently valuable for pursuing party goals. A party record can be valuable as a means to communicate to voters the types of policies that will emerge if the party were to win control of the legislative process. However, the party label is valuable to members only insofar as chamber majority status is indeed an immediate collective goal and the party organization is a viable means to achieve it. Given the individual costs described above, the value of a party-centric legislative organization strategy depends on the likelihood that such collective gains can in fact be reaped. This in turn depends on the extent to which control of the chamber is likely to change hands. It is in these competitive environments that collective competition between the parties should be most salient and the reputation of the party as a whole would be more likely to mean the difference between winning or losing control of the chamber.

The variable value of collective electoral goals should lead us to expect to see parties delegating power to party leaders when parties are in electoral competition to obtain or 
defend majority status. In chambers with a dominant majority party, the expected value of protecting or obtaining majority status is much less likely to outweigh member's costs of organizing the party, given that it would have little effect on the party's collective fortunes. The opposite can be said for highly competitive party environments. When political parties are in close competition for majority control of the chamber and small party vote swings can sway majority status, members can most clearly benefit from leaders with the power to strengthen their collective reputation. While any party may have incentives to constrain member behavior, a party holding a majority of seats is best positioned to exploit the kinds of tools highlighted in the Congressional literature, such as agenda control (Cox \& McCubbins 1993, Cox \& McCubbins 2005), bundling legislation (Sinclair 2002) and various selective incentives (Maltzman 1998, Lawrence, Maltzman \& Smith 2006).

Some evidence of a relationship between parties and legislative organization has already been noted in the literature on Congress and the state legislatures. With regard to party behavior, the one-party Rhode Island lower chamber and the non-partisan Nebraska chamber, for instance, have been known to lack structured voting behavior compared to competitive state chambers (Wright \& Osborn 2002, Wright \& Winburn 2003). Similarly, Jenkins (1999) compares the dimensionality of the policy space in the $19^{\text {th }}$ Century U.S. and Confederate Houses and shows that the mere existence of parties structures votes in such a way that legislators in the former chamber have more coherent behavior. ${ }^{2}$ If the collective-reputational motivations noted in the Congressional literature can be generalized as described above, we argue that this basic structuring influence of parties should be supplemented by continuous variation among parties in their incentives to exploit competitive environments.

With regard to the related issue of formal chamber rules, majority parties across state assemblies certainly vary in the types of gatekeeping tools that can be used to control the legislative process (Clucas 2001). Over time, these formal rules may be endogenous to the party organizational incentives of majorities. Clucas (2001) finds that speakers with stronger formal powers in U.S. state lower chambers tend to correspond to more competitive states.

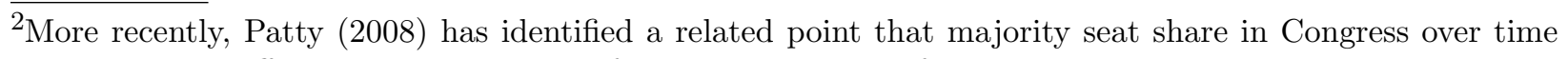
has predictable effects on the coherence of legislative behavior for the majority party. 
Since we focus on the behavioral organization of legislatures, subject to informal factors, we do not argue that formal chamber powers are a necessary condition for empowering party leadership. Rather, we argue that member behavior reflects the degree of authority delegated to the party leadership to use any formal powers that are available as well as to "exercise powers that are not actually given [to] them in the formal rules" (Clucas 2001, 324). In practice, the de facto power of party leaders will be largely a function of delegation through informal channels, which may or may not be supplemented by chamber rules (Battista 2011). We consider these as alternate mechanisms by which comparable behavioral goals can be achieved in different settings. Furthermore, party leaders' de facto power may even extend beyond the legislature itself. If the environment is sufficiently institutionalized, we would expect that the preferences of members can be shaped even before the election by legislative leader involvement in the candidate recruitment process, minimizing the need for legislative mechanisms. Indeed, consistent with our argument here, increased interparty competition correlates with party leaders in state assemblies being more active in recruiting candidates (Sanbonmatsu 2006).

In sum, legislative parties can exploit a variety of different tools - formal, informal, and extra-legislative - in order to aid the leadership in maintaining the coherence of their legislative parties. Observed behavior may reflect the cumulative effects of using these organizational tools, but will depend on the incentives to use them. Individually these have been related in various ways to interparty competition, or, as we interpret it, the prospects of winning and losing majority status.

Implications for the Structure of Legislative Voting. We assess the effects of party organization using legislative voting behavior as a reflection of the influence of all forms of legislative partisan organization. For these purposes, we focus on the degree of "predictability" in voting behavior (Jenkins 1999, Wright \& Schaffner 2002). In structured voting environments (i.e., centralized), where an underlying dynamic of conflict defines all votes, individual voting behavior can be predicted by a single dimension of variance. These "low-dimensional" legislative environments contain seemingly unrelated votes on issues that are connected by 
a basic underlying dynamic, such as "liberal-conservative" or another ideological conflict. Votes are "predictable" when an individual's behavior on specific votes can be inferred from their position within this underlying dynamic. By contrast, unstructured legislative environments, consisting of spontaneous short-term interactions, are characterized by uncertainty and complex coalitions. Because these votes are disconnected, this results in a less predictable multi-dimensional voting pattern. While ideological cues provide some simplification to a repeated voting environment when legislators vote sincerely on policy and are fully informed of policy consequences (Poole 2005), party organizations are widely believed to substantially institutionalize the simplification of legislative choices (Aldrich 1995, Sinclair 2002). With parties to simplify the individual choices of legislators, the complexity of a legislative choice environment diminishes dramatically (Jenkins 1999, Wright \& Schaffner 2002).

While almost all legislatures have parties that introduce some structure to behavior, the degree of partisan involvement in the organization should relate to overall patterns of predictability in voting. Together, the arguments above imply that parties in legislatures with the greatest incentives to organize voting (competitive party systems) should correspond to members whose individual voting records are more predictable than those where those incentives are weakest (uncompetitive party systems), while the most predictable voters within these parties should be those facing the safest districts.

\section{Data And MEASUREMEnts}

We test our argument using legislative voting behavior and individual and party electoral outcomes in combination with chamber characteristics in the U.S. upper and lower state chambers during the 1999-2000 legislative sessions. Testing this theory in U.S. states using cross-sectional data provides a political environment with wide variation in individual and party electoral competition across states and within states. Because states and state chambers have unique group-level effects on legislative and voting behavior (i.e., legislator

observations in each state and chamber are interdependent within state and state chamber 
clusters), we employ a multi-level linear regression with random intercepts to account for unmeasured variation in both the underlying state and chamber-level effects.

Measuring Coherent Parties and Unpredictable Behavior. We argue that the effects of parties constraining choices can be observed as low dimensional voting behavior - that is, easily predicted by spatial voting models. With this we aim to measure the consistency of voting - the extent to which "frequent and dramatic changes in voting behavior undermine the value of the party label" (Kiewiet \& McCubbins 1991, 43). We can measure this for each legislator from the one-dimensional W-NOMINATE spatial model of voting using the model's correct classification rate. The classification rate reflects the degree to which a onedimensional spatial model can correctly classify actual voting behavior (Poole \& Rosenthal 1997). ${ }^{3}$ Related aggregate fit statistics for roll calls are often at the chamber level to assess the overall dimensionality of voting (Jenkins 1999, Wright \& Osborn 2002, Wright \& Winburn 2003).

By contrast to previous work, we measure this concept of predictable voting at the individual level. For individual legislators, the classification rate is larger for members whose behavior is better explained by the first dimension of the roll call data - those making the fewest "errors" from the perspective of a one-dimensional spatial model. "Error" here refers to instances when individual legislator votes (yea or nay) are not accurately predicted by the spatial model (i.e., the vote prediction is located on the opposite side of the cutting point than the observed position). The classification rate for each individual legislator is derived from the individual vote errors to determine how accurately the W-NOMINATE scaling procedure can predict a legislator's overall voting behavior along a single dimension (Poole

\footnotetext{
${ }^{3} \mathrm{~A}$ coherent party reputation should be consistent and voters should be able to make accurate predictions about the types of policy that the party would pursue if in office (American Political Science Association 1950, Cox \& McCubbins 1993, Cox \& McCubbins 2005, Kiewiet \& McCubbins 1991). A low dimensional voting environment indicates that legislators are voting consistently with those who are spatially proximate along a given dimension. In these low dimension environments, voters can determine the future direction of policy with little information (e.g., the spatial position of proposed policy and the status quo policy). Note that even a party with many "moderate" or "disloyal" members can be still retain low dimensional and coherent ideological structure to voting. Whereas party loyalty reflects the size of the voting coalition, classification error reflects the consistency of members voting within a coalition across votes.
} 
\& Rosenthal 1997). ${ }^{4}$ A high classification rate means that the member's voting coalitions can be consistently predicted in a one-dimensional space. A low classification rate means that one-dimensional measures of a member's spatial location cannot routinely predict which voting coalitions she would join. Behavior is "idiosyncratic" or "unpredictable" in the sense that there are a large number of potential voting coalitions that a legislator is likely to join. We use Wright's (2004) roll call data from the 1999-2000 U.S. state sessions ${ }^{5}$ to calculate individual classification rates.

Individual and Party Electoral Competition. Individual competition is calculated using Carsey et al.'s (2007) State Legislative Election Returns, 1967-2003. For most legislative districts, this is a simple calculation that is the percent of total votes that separates the winner from the runner-up (i.e., the margin of victory) in plurality single-member districts (SMD). ${ }^{6}$ Because we are concerned about the threats to losing a seat in the election, we use the natural log of each candidate's percentage margin of victory. The log transformation captures the intuition that increasing the margin of victory between the winner and the runner-up has a diminishing effect on the degree to which that seat is "safe." That is, the change in the threat to losing a seat between one percent and ten percent margin of victory is more important, in terms of influencing a legislator's voting behavior, than further increases in an already large margin.

\footnotetext{
${ }^{4}$ The classification rate is determined using the following formula for each legislator: $\frac{\text { CorrectlyPredictedVotes }}{\text { TotalVotes }} \times 100$.

${ }^{5}$ Arkansas, Kentucky, Montana, North Dakota, Nevada, Oregon, and Texas have biennial sessions. 2000 session data was unavailable for New York. 2001 session data was used for Arkansas because 1999 session data was unavailable.

${ }^{6}$ This calculation is more complicated in multi-member districts (MMD) and in districts where there is crosslisting. A similar approach is used in MMD as above in SMD. For each winner we calculate the percent difference from the first loser. In these districts, the first loser is the candidate that has the most votes among those who do not win a seat. The intuition here is that candidates are competing to win enough votes to earn a seat, rather than competing to win the most votes possible. Thus, legislators, in terms of their voting behavior, are responding to their risk of not winning a seat. Where cross-listing is possible, we aggregate total votes earned by each candidate across party affiliation and determine the percent vote difference between the winner(s) and the runner-up (or, first loser). New York is the only state in our sample that allows for cross-listing. We assume that cross-listed candidates are responding to their immediate threat to winning, irrelevant of party affiliation. Each of these calculations captures how close the individual legislator is from losing the election. In the appendix, we examine this case and find that this captures additional variation in partisan dependence that is consistent with our argument here.
} 
Party competition is calculated based on the the same Carsey et al. (2007) state elections data. This is determined after aggregating the number of votes for each candidate affiliated with the party for each chamber election. Cross-listed candidates have their votes distributed across each party based upon how many votes they won affiliated with that party. Party competition is the absolute percent difference between the two major parties in the chamber (i.e., Democrats and Republicans). Smaller differences indicate that the parties are highly competitive in terms of their ability to gain or lose majority status in the chamber. Individual party votes are aggregated to demonstrate how (un)successful the party is overall in the election. We use the log transformation from the percent difference to capture the diminishing threat of losing the majority (or likelihood of winning the majority) as the party wins more votes in the aggregate. Majority party status and membership is determined using Klarner's (2003) State Legislative Partisanship data.

Sample Selection \& Empirical Model. Chamber data-majority party affiliation and individual W-NOMINATE classification rates - are matched to the legislators' electoral data in the election that precedes the 1999-2000 session ${ }^{7}$ and party competition from the election cycle directly preceding the 1999-2000 session. We were able to match almost every legislator in the Wright (2004) data with the district election that precedes the legislative session from Carsey et al. (2007), resulting in 95 percent (7253 out of 7617) successful matches.

The empirical model includes the direct effect for each of the above independent variables (majority party status, log legislator margin of victory, and log party vote difference). We expect to observe relatively more predictable behavior (i.e., more one-dimensional behavior) for "safe" legislators in either party and overall for legislators in the majority party. ${ }^{8}$ Our unit of analysis is the individual legislator. Descriptive plots of the distribution of the dependent variable - classification rate - separated by state and chamber are presented in the Appendix (see Figure 3). Because there are distinct patterns of variation between states

\footnotetext{
${ }^{7}$ Legislators with two-year terms are elected in the election cycle directly preceding the 1999-2000 session. Legislators with four-year terms are elected in the election two cycles prior.

${ }^{8}$ That is, we expect a result in which legislator margin of victory is positive and significant and log party vote difference is negative and significant for all legislators, and where majority party members generally have lower dimensional behavior across all variables (i.e., majority party indicator is positive and significant).
} 
and state chamber and dependence between legislator observations in the same chamber and state, we use a hierarchical model with random intercepts for each state and chamber.

We adopt three primary constraints to our sample. Because we rely on the concept of majority status, we eliminate from our sample those chambers where there is no majority party (Washington's House) and non-partisan elections (Nebraska). ${ }^{9}$ Second, we remove those chambers where there is a sufficiently high number of missing electoral district data so as to be impossible to accurately calculate party and individual electoral margins (Arkansas, Florida, Louisiana, Oklahoma, and Vermont). ${ }^{10}$ Finally, we remove unchallenged seats and leave only those who had to compete in the election (i.e., winning electoral candidates had to face a challenger and win less than 100 percent of the vote). This constraint reduces the sample size by just under two thousand observations. The rationale for this is that the high frequency of unchallenged candidates/non-competitive races could bias the sample. We remove these types of elections so that the extremes of the sample do not determine the result. This leaves us with a more continuous measurement of log legislator margin of victory and log party vote difference without observations clustered at the extreme.

The resulting dataset combines individual and party electoral outcomes with legislator W-NOMINATE fit statistics in the U.S. states for the 1999-2000 legislative session. This allows us a unique ability to evaluate behavior in the U.S. states using individual electoral performance, providing us with over four thousand and three hundred legislator observations across eighty-seven U.S. state legislative chambers.

\section{FINDINGS}

Table 1 presents the results from our evaluation. Our primary variables of interests, log party vote difference and log legislator margin of victory, are both statistically significant

\footnotetext{
${ }^{9}$ However, including Nebraska as effectively a "dominant party" type case and including Washington's House with either party coded as a majority does not substantially effect the results presented below.

${ }^{10}$ Districts were considered missing if candidate party affiliations were unknown and/or vote data was missing. Chambers were removed from the sample if ten percent of districts were missing, this includes: Arkansas (lower chamber, 66 percent missing; upper chamber, 58 percent missing); Florida (lower chamber, 60 percent missing; upper chamber, 65 percent missing); Louisiana (lower chamber, 30 percent missing; upper chamber 32 percent missing); Oklahoma (lower chamber, 42 percent missing; upper chamber, 38 percent missing); and Vermont (lower chamber, 100 percent missing; upper chamber, 100 percent missing).
} 
$(\mathrm{p} \leq .01)$ and in the expected direction (positive and negative, respectively). In addition, we also find that majority party members are systematically more predictable than those in the minority party - the majority party effect is positive and statistically significant $(\mathrm{p} \leq .01)$. We also find substantively similar effects when we evaluate our model using the full sample, which includes the two thousand legislator observations that were elected from unchallenged elections. These results are also presented in Table 1 and show that each of the findings remain largely unchanged. ${ }^{11}$

\section{- Table 1 about here-}

To illustrate the results, we produce simulations from our model applying the method described in King, Tomz \& Wittenberg (2000) and Tomz, Wittenberg \& King (2001). The simulations are based on the underlying "average" model for all chambers and legislators. Figure 1 graphically shows the predicted effects of varying log party vote difference and holding log legislator margin at its mean for a legislator in the majority and in the minority party. We see that for all legislators there is a strong negative relationship between the one-dimensional voting predictability and the competitiveness of the party system. This is consistent with our main claim that parties should become more coherent in their behavior as the incentives for maintaining a clear partisan reputation become strongest. We also see that, all else equal, legislators in the majority party are also generally more predictable than those in the minority party, indicating a systematic tendency for more coherent behavior for the majority parties. In the distribution of the classification rate across states and chambers, the mean is equal to 87 percent and a standard deviation equal to 7 percentage points (see 'ALL' plot in Figure 3 in the Appendix). These simulations highlight the substantive shift

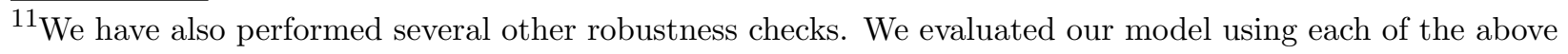
samples - the full sample and only challenged candidates - including the states removed due to an insufficient proportion of districts with usable electoral data and find substantively similar results. We have also examined our model using an alternative dependent variable measure, the Geometric Mean Probability(GMP), in place of the classification rate and find substantively similar results across each of the samples. Legislator GMP and the classification rate are correlated at .95. Finally, we evaluate our models replacing aggregate party electoral competition (log party vote difference) with partisan composition in the chamber(the logged percent seat difference between the two largest parties) and, once again, find substantively similar results. Although partisan electoral competition and partisan composition capture two distinct concepts (see Barrilleaux, Holbrook \& Langer (2002)), and electoral competition is the more direct in capturing the quantity of interest, the results are robust to either measure.
} 
within the observed range of the data: a difference of 92 to 87 percent for legislators in the majority party and 89 to 84 percent for legislators in the minority party as aggregate party margins widen.

\section{-Figure 1 about here-}

Using the same approach from above, we draw simulations from the underlying "average" model to graphically show the predicted effects of varying log legislator margin of victory for majority and minority party members, holding log party vote difference at its mean. Consistent with the theoretical argument, the simulations show that there is a positive relationship between the legislators' apparent voting constraints and the individual margin of victory for all legislators (see Figure 2). As with Figure 1, the range of the y-axis is based on the distribution of the observed range. This again represents a substantial shift- from 86 to 89 percent for majority party members and 83 and 86 percent for minority party members - as legislator margins widen. This provides evidence that the least constrained partisans are restricted to those members for whom the party label is least valuable for reelection. We also see again that legislators in the majority party have more predictable behavior on average than those in the minority party. This is consistent with the notion that majority parties have greater access to the types of resources used to systematically constrain the behavior of those members who face the least pressure to vote with coalitions based on district specific considerations.

\section{-Figure 2 about here-}

Taken together, the results support the argument that parties operating in more competitive electoral environments are more likely to have party members with more predictable behavior. Further, the highest error rates within the party are associated with members elected from the most vulnerable districts - those who would be the costliest to constrain given that they face the greatest competing need to respond to changing electoral constituencies across issues and the least benefit from their party reputation. The results also demonstrate that the majority party has an advantage when it comes to organizing the party to create more 
predictable behavior. Though both parties may have generally oriented around stable longterm competition patterns, this difference conforms to literature that suggests that majority parties have an immediate advantage in constraining choices and organize chambers.

\section{Conclusion}

Cox \& McCubbins $(1993,2005)$ have argued that the party reputation can serve as a collective good for a political party, the pursuit of which motivates a delegation of power to its leadership to cultivate it. Implicit in this argument is the assumption that the benefits from developing a party record must be consistently present. We have argued that the benefits of creating a coherent party record vary not only across legislators, but across parties facing different electoral environments. For the costs of this delegation to be overcome by its benefits, the party reputation must provide an asset in achieving a collective goal: the achievement or retention of majority status. We argue that competitive party systemswhere parties are of similar electoral size - provide the optimal environment for parties to organize internally. These results follow the suggestion by Clucas (2001, 322): "if a party's record can also affect members' reelection, then it is possible that as competition increases, members will also become more concerned about their party's output, since the party's output would then have a greater potential to affect their reelection goal." Situations of more dominant majority parties are, by contrast, far less conducive to producing incentives to delegate to leaders the power to build coherent party records.

When incentives for legislative political parties to centralize exist, parties can utilize a variety of different tools in order to manage party reputation and employ their strength at different levels of governing to achieve party coherence. These tools may be interchangable and complimentary for managing the party organization. Party leaders can actively participate in recruiting candidates who will improve party coherence after the election. In the chamber, however, even parties with substantial leader involvement with recruitment are ultimately subject to the incentives for incumbent members to protect their own reputations 
at the expense of the party. As we have shown, the least predictable voting behavior corresponds to vulnerable legislators in the most competitive districts. Leaders must then also utilize legislative tools to further manage the voting behavior of their members and build a coherent record once the legislative session begins. As we have discussed, additional legislative tools may include agenda control, bundling legislation or using selective incentives to balance the electoral costs of partisan behavior. In this process, parties may formally delegate institutional powers to party leaders to control the legislative process, but informal channels of delegation can ultimately determine the extent to which party leaders can employ those powers (Rohde 1991). The aggregate effects of these types of organizational tools (formal and informal, intra and extra-legislative) capture the larger picture of legislative party organization. We argue that the incentives to use any of these strategies, in isolation or in combination, are conditional on interparty competition in elections.

Using individual level data on the spatial predictability of the voting records of U.S. state legislators, we examined whether seemingly consistent reputational incentives for party organization are in fact dependent on the competitive environment. We find that indeed political parties have more predictable, one-dimensional member behavior when the party system is competitive, which we take as a consequence of parties whose members have empowered leaders with the authority to strengthen their organizations in the ways just described. We further found that the majority party has more predictable member voting in general. Although majority and minority parties should face similar incentives in this regard over the long term, the majority parties appear to be better positioned to constrain immediate member behavior.

The prior literature has suggested that political parties do coordinate behavior in such a way to create more predictable "low dimensional" chambers in general (Jenkins 1999, Wright \& Osborn 2002, Wright \& Winburn 2003). Our findings suggest that the intuition of Cox \& McCubbins (1993) can be generalized to demonstrate that political parties strategically develop coherent parties in response to the expected value of party records and constrain the behavior of members facing the fewest electoral costs. 


\section{REFERENCES}

Aldrich, J.H. 1995. Why parties?: The origin and transformation of political parties in America. University of Chicago Press.

American Political Science Association. 1950. Toward a more responsible two-party system, a report. New York: Rinehart.

Ansolabehere, S., J.M. Snyder \& C. Stewart. 2001. "Candidate positioning in US House elections." American Journal of Political Science 45(1):136-159.

Barrilleaux, C., T. Holbrook \& L. Langer. 2002. "Electoral competition, legislative balance, and American state welfare policy." American Journal of Political Science pp. 415-427.

Battista, J.C. 2011. "Formal and perceived leadership power in US state legislatures." State Politics 8 Policy Quarterly 11(1):102.

Berry, W.D., M.B. Berkman \& S. Schneiderman. 2000. "Legislative professionalism and incumbent reelection: The development of institutional boundaries." The American Political Science Review 94(4):859-874.

Bishin, B. 2009. Tyranny of the minority: The subconstituency politics theory of representation. Temple University Press.

Canes-Wrone, B., D.W. Brady \& J.F. Cogan. 2002. "Out of step, out of office: Electoral accountability and House members' voting." American Political Science Review 96(01):127-140.

Carsey, T. M., W. D. Berry, R. G. Niemi, L. W. Powell \& J. M. Snyder. 2007. "State Legislative Election Returns, 1967-2003." Release Version 4 ICPSR 21480.

Carson, J.L., G. Koger, M.J. Lebo \& E. Young. 2010. "The electoral costs of party loyalty in Congress." American Journal of Political Science 54(3):598-616.

Clucas, R.A. 2001. "Principal-agent theory and the power of state house speakers." Legislative Studies Quarterly 26(2):319-338.

Cox, G.W. \& M.D. McCubbins. 1993. Legislative leviathan: Party government in the House. University of California Press.

Cox, G.W. \& M.D. McCubbins. 2005. Setting the agenda: Responsible party government in the US House of Representatives. Cambridge Univ Press.

Evans, D. 1994. "Policy and pork: The use of pork barrel projects to build policy coalitions in the House of Representatives." American Journal of Political Science 38(4):894-917.

Evans, D. 2004. Greasing the wheels: Using pork barrel projects to build majority coalitions in Congress. Cambridge University Press. 
Hager, G.L. \& J.C. Talbert. 2000. "Look for the party label: Party influences on voting in the US House." Legislative Studies Quarterly 25(1):75-99.

Hogan, R.E. 2008. "Policy responsiveness and incumbent reelection in state legislatures." American Journal of Political Science 52(4):858-873.

Jenkins, J.A. 1999. "Examining the bonding effects of party: A comparative analysis of roll-call voting in the US and Confederate houses." American Journal of Political Science 43(4):1144-1165.

Kiewiet, D.R. \& M.D. McCubbins. 1991. The logic of delegation: Congressional parties and the appropriations process. University of Chicago Press.

King, G., M. Tomz \& J. Wittenberg. 2000. "Making the most of statistical analyses: Improving interpretation and presentation." American Journal of Political Science 44(2):347-361.

Klarner, C. 2003. "The measurement of the partisan balance of state government." State Politics E Policy Quarterly 3(3):309-319.

Lawrence, E.D., F. Maltzman \& S.S. Smith. 2006. "Who wins? Party effects in legislative voting." Legislative Studies Quarterly 31(1):33-69.

Maltzman, F. 1998. Competing principals: Committees, parties, and the organization of Congress. University of Michigan Press.

Mayhew, D.R. 1974. Congress: The electoral connection. Yale University Press.

Patty, J.W. 2008. "Equilibrium party government." American Journal of Political Science 52(3):636-655.

Poole, K.T. 2005. Spatial models of parliamentary voting. Cambridge University Press.

Poole, K.T. \& H. Rosenthal. 1997. Congress: A political-economic history of roll call voting. New York: Oxford University Press.

Rahn, W.M. 1993. "The role of partisan stereotypes in information processing about political candidates." American Journal of Political Science 37(2):472-496.

Rohde, D.W. 1991. Parties and leaders in the postreform House. University of Chicago Press.

Sanbonmatsu, K. 2006. "The legislative party and candidate recruitment in the American states." Party Politics 12(2):233-256.

Schaffner, B.F. \& M.J. Streb. 2002. "The partisan heuristic in low-information elections." Public Opinion Quarterly 66(4):559-581.

Schlesinger, J.A. 1991. Political parties and the winning of office. University of Michigan Press.

Sinclair, B. 1995. House special rules and the institutional design controversy. In Positive theories of congressional institutions, ed. K. A. Shepsle \& B. R. Weingast. University of Michigan Press pp. 235-252.

Sinclair, B. 2002. Unorthodox Lawmaking. CQ Press.

Smith, S.S. 2000. "Positive theories of congressional parties." Legislative Studies Quarterly 25(2):193-215. 
Snyder, J.M. \& M.M. Ting. 2002. "An informational rationale for political parties." American Journal of Political Science 46(1):90-110.

Snyder, J.M. \& M.M. Ting. 2003. "Roll calls, party labels, and elections." Political Analysis 11(4):419-444.

Tomz, M., J. Wittenberg \& G. King. 2001. "CLARIFY: Software for interpreting and presenting statistical results, Version 2.0." http://gking.harvard.edu.

Woon, J. \& J.C. Pope. 2008. "Made in Congress? Testing the electoral implications of party ideological brand names." The Journal of Politics 70(03):823-836.

Wright, G. C. \& J. Winburn. 2003. "The effects of size and party on the dimensionality of roll calls." paper presented at the $61^{\text {st }}$ annual meeting of the Midwest Political Science Association, Chicago, IL.

Wright, G. C. \& T. Osborn. 2002. "Party and roll call voting in the American legislature." paper presented at the $60^{\text {th }}$ annual meeting of the Midwest Political Science Association, Chicago, IL.

Wright, G.C. 2004. "Representation in America's Legislatures." Indiana University, National Science Foundation Grant.

Wright, G.C. \& B.F. Schaffner. 2002. "The influence of party: Evidence from the state legislatures." American Political Science Review 96(02):367-379. 
TABLE 1. Predictable Legislative Behavior in U.S. States, 1999-2000

\begin{tabular}{|c|c|c|}
\hline Variable & $\begin{array}{c}\text { Constrained } \\
\text { Sample }\end{array}$ & $\begin{array}{c}\text { Full } \\
\text { Sample }\end{array}$ \\
\hline \multicolumn{3}{|c|}{ Equation 1 : Fixed Effects } \\
\hline Legislator Margin (logged) & $\begin{array}{l}0.33^{* *} \\
(0.08)\end{array}$ & $\begin{array}{l}0.19^{* *} \\
(0.07)\end{array}$ \\
\hline Majority Party & $\begin{array}{l}2.99^{* *} \\
(0.19)\end{array}$ & $\begin{array}{l}2.90^{* *} \\
(0.16)\end{array}$ \\
\hline Party Vote Difference (logged) & $\begin{array}{l}-0.88^{* *} \\
(0.30)\end{array}$ & $\begin{array}{l}-0.99^{* *} \\
(0.30)\end{array}$ \\
\hline Intercept & $\begin{array}{l}86.54^{* *} \\
(0.84)\end{array}$ & $\begin{array}{l}87.06^{* *} \\
(0.85)\end{array}$ \\
\hline \multicolumn{3}{|c|}{ Equation 2 : State } \\
\hline Intercept & $\begin{array}{l}0.88^{* *} \\
(0.16)\end{array}$ & $\begin{array}{c}0.99^{* *} \\
(0.14)\end{array}$ \\
\hline \multicolumn{3}{|c|}{ Equation 3 : State Chamber } \\
\hline Intercept & $\begin{array}{l}0.72^{* *} \\
(0.13)\end{array}$ & $\begin{array}{l}0.66^{* *} \\
(0.13)\end{array}$ \\
\hline Equation 4 : & Residual & \\
\hline Intercept & $\begin{array}{l}1.78^{* *} \\
(0.01)\end{array}$ & $\begin{array}{l}1.78^{* *} \\
(0.01)\end{array}$ \\
\hline States & 44 & 44 \\
\hline State Chambers & 87 & 87 \\
\hline Total Observations & 4397 & 6343 \\
\hline
\end{tabular}

Significance levels : $\quad \dagger: 10 \% \quad *: 5 \% \quad * *: 1 \%$

Standard Errors in parentheses. 
FiguRE 1. Legislator Predictability and Party Competition

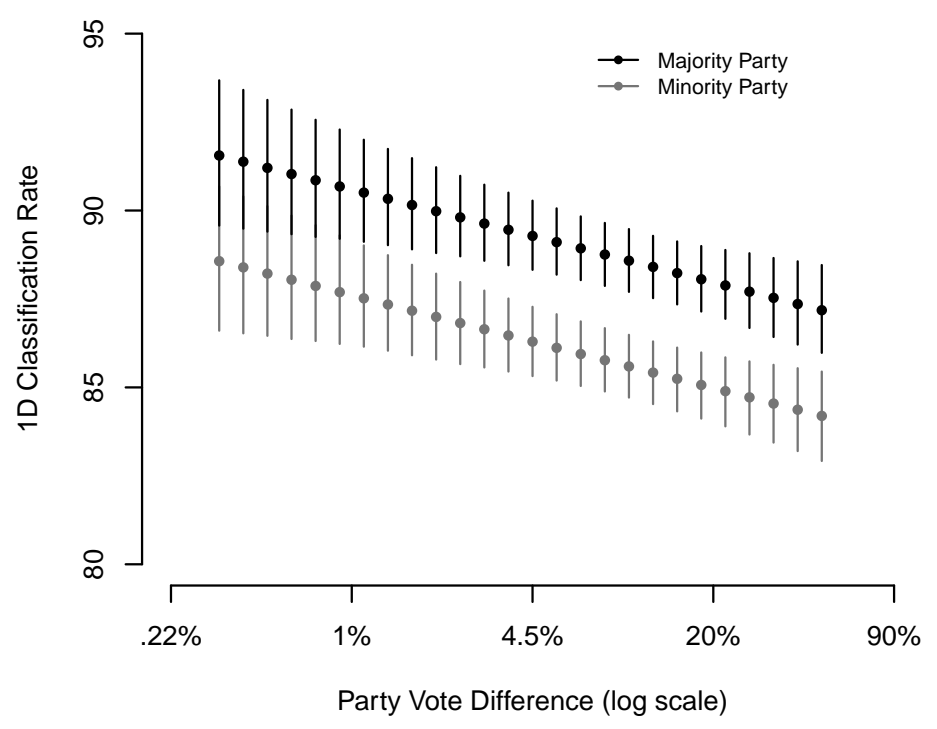

FiguRE 2. Legislator Predictability and Individual Competition

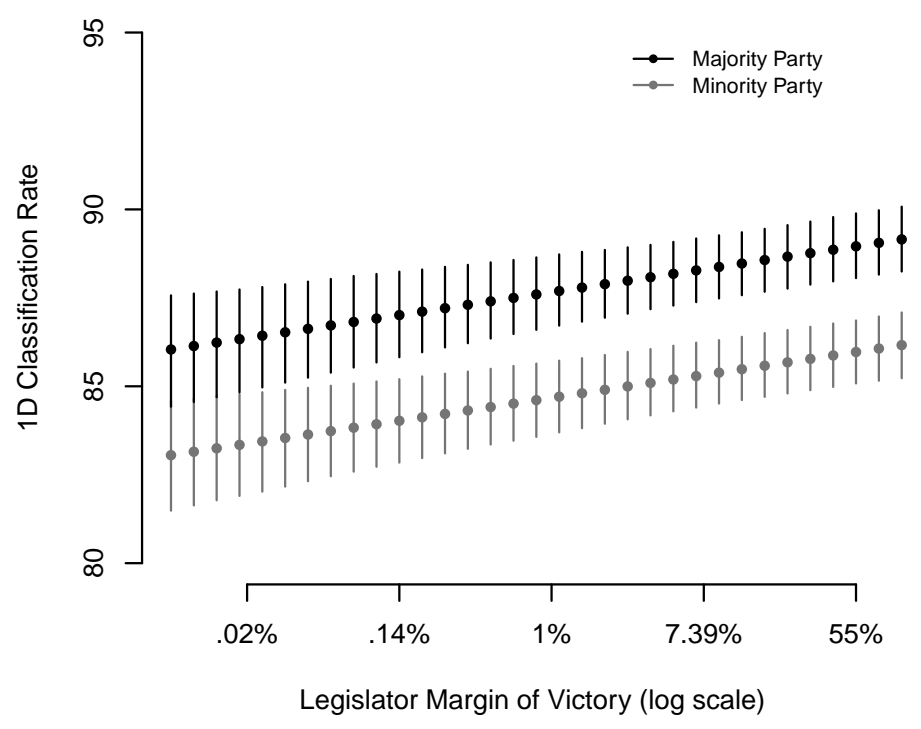




\section{Appendix}

Figure 3. Density Plots of Full Sample

\section{D Classification Rate by State and Chamber}

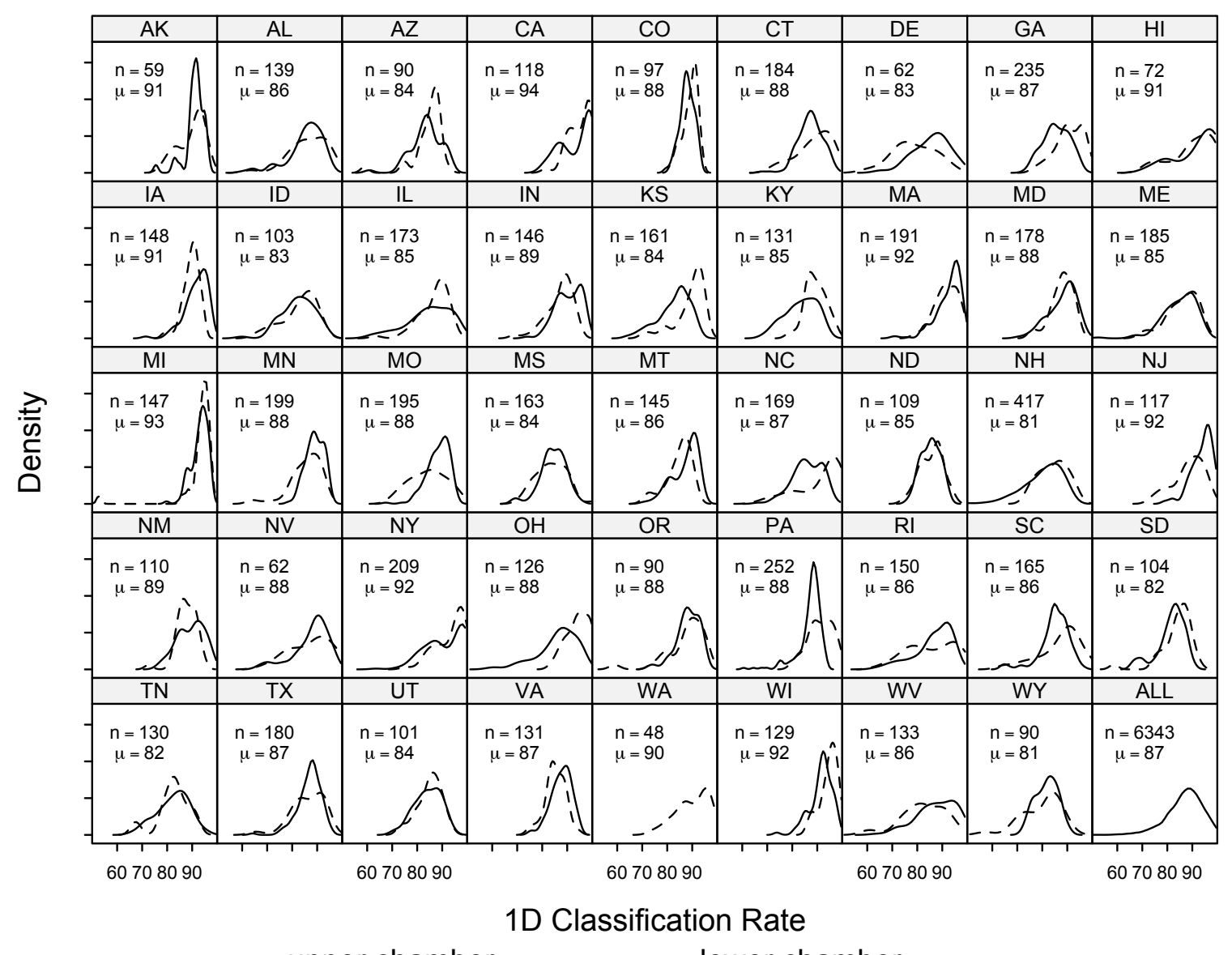

upper chamber -.... lower chamber

Full Sample 


\section{Supplementary Analysis of Cross-Party Support in New York}

We have argued that when individual legislators rely more on cultivating support beyond their party affiliates, individual voting behavior will tend to be less predictable. Above, we suggest that individual vote margins capture a significant portion of this variation and that we can interpret this measure similarly across states. In the state of New York, however, additional variation can be directly measured to capture the cultivation of votes outside of one's party because of the fusion candidacies that allow for affiliations with more than one party on the electoral ballot in elections.

Although cross-party appeals may be distinct from catering to constituent groups, obtaining support from separate minor party organizations reflects an effort at cultivating an individualizing distinction. When candidates cross-list, they can win votes across those parties with whom they affiliate. We can use this information to determine the extent to which a legislator relied on one or more parties to win the election. Here, we presume that a legislator who won with a larger share of her votes from one party is seen as benefiting more from the reputation of that party than a legislator with her vote share distributed across multiple parties. In the latter case, party reputation is not the only factor the determines the outcome of the election.

Limiting our sample to New York allows us to take advantage of intra-state variation between legislators who won votes concentrated in one party and those who won votes across multiple parties. This variation is lost when evaluated across states because of the high frequency of observations clustered at values where legislators won all of their votes from one party. Using the same data as before, our measure comes from the party with whom the legislator won the most votes. The value is the natural log of the percent of total votes won from that largest party. We take the natural log for the same reasons that are

explained above. We test the same model as above and include our new measure for the 
votes won from a candidate's own party. We evaluate two models using Ordinary Least Squares, the first includes Legislator Margin and the second excludes Legislator Margin. ${ }^{12}$

TABle 2. Predictable Legislative Behavior in New York, 1999

\begin{tabular}{|c|c|c|}
\hline Variable & Model 1 & Model 2 \\
\hline Legislator Margin (logged) & $\begin{array}{c}1.93^{* *} \\
(0.53)\end{array}$ & \\
\hline Votes From Party (logged) & $\begin{array}{l}9.15^{*} \\
(3.90)\end{array}$ & $\begin{array}{l}11.61^{* *} \\
(3.97)\end{array}$ \\
\hline Majority Party & $\begin{array}{l}10.31^{* *} \\
(0.77)\end{array}$ & $\begin{array}{l}10.25^{* *} \\
(0.80)\end{array}$ \\
\hline Party Vote Difference (logged) & $\begin{array}{l}-1.87^{\text {** }} \\
(0.48)\end{array}$ & $\begin{array}{l}-2.01^{* *} \\
(0.50)\end{array}$ \\
\hline Intercept & $\begin{array}{c}40.45^{*} \\
(17.13)\end{array}$ & $\begin{array}{c}36.99^{*} \\
(17.68)\end{array}$ \\
\hline $\begin{array}{l}\text { Total Observations } \\
\mathrm{R}^{2}\end{array}$ & $\begin{array}{r}182 \\
0.56\end{array}$ & $\begin{array}{r}182 \\
0.53\end{array}$ \\
\hline $\begin{array}{l}\text { Significance levels : } \quad \dagger: 10 \% \quad *: \\
\text { Standard Errors in parentheses. }\end{array}$ & $5 \% \quad * *: 1 \%$ & \\
\hline
\end{tabular}

The empirical results show that legislators with a larger concentration of vote share in one party are more likely to demonstrate predictable voting behavior than those with vote shares distributed across multiple parties, even when controlling for legislator vote margins. This additional analysis is further evidence in support of the relationship between apparent ideological voting and party dependence.

\footnotetext{
${ }_{12}$ Although we expect Party Vote Difference to have the same predicted effect as above, we cannot completely rule out that chamber effects are being captured by Party Vote Difference because the measure is constant within chamber.
} 